ORNL/TM-2020/1552

\title{
2019 Quantum Materials Young Investigators Workshop Report
}

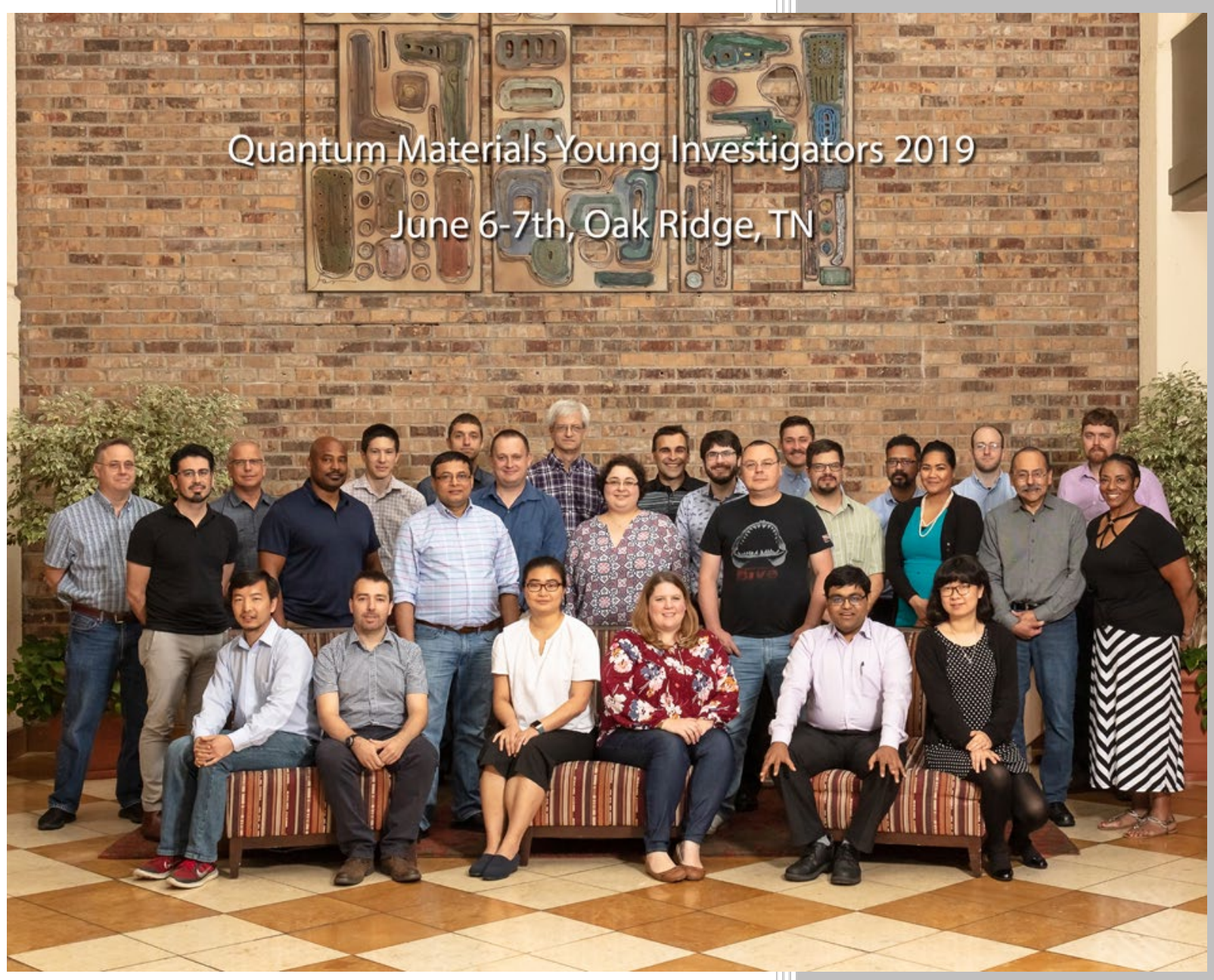

OAK RIDGE NATIONAL LABORATORY MANAGED BY UT-BATTELLE FOR THE US DEPARTMENT OF ENERGY

Adam Aczel Stuart Calder

Date: Sept. 24, 2019 


\section{DOCUMENT AVAILABILITY}

Reports produced after January 1, 1996, are generally available free via US Department of Energy (DOE) SciTech Connect.

Website http://www.osti.gov/scitech/

Reports produced before January 1, 1996, may be purchased by members of the public from the following source:

National Technical Information Service

5285 Port Royal Road

Springfield, VA 22161

Telephone 703-605-6000 (1-800-553-6847)

TDD 703-487-4639

Fax 703-605-6900

E-mail info@ntis.gov

Website http://www.ntis.gov/help/ordermethods.aspx

Reports are available to DOE employees, DOE contractors, Energy Technology Data Exchange representatives, and International Nuclear Information System representatives from the following source:

Office of Scientific and Technical Information

PO Box 62

Oak Ridge, TN 37831

Telephone 865-576-8401

Fax 865-576-5728

E-mail reports@osti.gov

Website http://www.osti.gov/contact.html

This report was prepared as an account of work sponsored by an agency of the United States Government. Neither the United States Government nor any agency thereof, nor any of their employees, makes any warranty, express or implied, or assumes any legal liability or responsibility for the accuracy, completeness, or usefulness of any information, apparatus, product, or process disclosed, or represents that its use would not infringe privately owned rights. Reference herein to any specific commercial product, process, or service by trade name, trademark, manufacturer, or otherwise, does not necessarily constitute or imply its endorsement, recommendation, or favoring by the United States Government or any agency thereof. The views and opinions of authors expressed herein do not necessarily state or reflect those of the United States Government or any agency thereof. 
Neutron Sciences Directorate

Report from the

'2019 Quantum Materials Young Investigators Workshop'

June 6-7, 2019

Adam Aczel

Stuart Calder

Date Published:

Sept. 24, 2019

Prepared by

OAK RIDGE NATIONAL LABORATORY

Oak Ridge, Tennessee 37831-6283

managed by

UT-BATTELLE, LLC

for the

US DEPARTMENT OF ENERGY

under contract DE-AC05-00OR22725 


\section{CONTENTS}

Page

EXECUTIVE SUMMARY 6

1. History and Charge of Quantum Materials Young Investigators Workshop Series 7

2. 2019 Workshop Agenda and Participants 7

3. Brief History of Neutron Scattering at ORNL 9

4. Quantum Materials Young Investigator Science 10

5. The Quantum Materials Initiative in the Neutron Sciences Directorate 10

6. Neutron Scattering Instrument Suites

6.1 Powder Diffraction $\quad 11$

6.2 Single Crystal Diffraction $\quad 11$

6.3 Direct Geometry Spectroscopy 11

6.4 Triple Axis Spectroscopy 11

6.5 Small Angle Neutron Scattering 12

6.6 Reflectometry 12

$\begin{array}{ll}\text { 7. Sample Environment } & 12 \\ 7.1 \quad \text { Sample Environment Steering Committees } & 12\end{array}$

7.2 Low Temperature, High Magnetic Fields 12

$\begin{array}{lll}7.3 & \text { High Pressure } & 14\end{array}$

8. Future Neutron Scattering and Complementary Capabilities at ORNL
8.1 HFIR Cold Guide Hall Re-optimization

8.2 MANTA 15

$\begin{array}{lll}\text { 8.3 Second Target Station } & 15\end{array}$

8.4 Muon Spectroscopy Facility 15

9. Data Reduction, Visualization, and Analysis 16

10. General Participant Feedback and Testimonials 16

11. Quantum Materials Young Investigators Master List and Past Workshop Participants 20 


\section{EXECUTIVE SUMMARY}

The fourth edition of the workshop "Quantum Materials Young Investigators" was held June 6-7, 2019 at the Oak Ridge National Laboratory (ORNL). This workshop followed up on previous meetings that took place at ORNL starting in 2016. This important series of annual workshops, organized by Adam Aczel and Stuart Calder, ensures continuous engagement with the early career principal investigators (PIs) of the quantum materials neutron scattering community. Through a series of short scientific talks presented by the external PIs, members of the Neutron Scattering Division (NSD) learn about their scientific interests and needs. Presentations from ORNL staff members also help to inform the external PIs about the current state of ORNL's quantum materials neutron scattering program. Topics covered include the current instrument suites, sample environment, data reduction, visualization, and analysis, and future neutron scattering and complementary capabilities. Feedback is solicited from the external PIs in all these key areas and communicated to NSD management in the form of a workshop report. This workshop series also helps to foster collaborations between NSD scientists and the research groups of the external PIs and plays an important role in attracting new neutron scattering users. 


\section{HISTORY AND CHARGE OF QUANTUM MATERIALS YOUNG INVESTIGATORS WORKSHOP SERIES}

The Quantum Materials Young Investigator Workshop Series began in 2016 at the request of Steve Nagler, when he was the Quantum Condensed Matter Division Director. Steve thought that a yearly workshop for external early career scientists $(<10-15$ years past their Ph.D.) would be a great way to advertise our neutron scattering capabilities to them, solicit important feedback about the user program on a wide range of topics, present our future plans for the program, and foster new collaborations between the external scientists and ORNL staff members. Adam Aczel and Stuart Calder were initially selected to organize this workshop series as co-PIs. They have now organized and ran a new workshop in this series once per year since 2016.

\section{2019 WORKSHOP PARTICIPANTS AND AGENDA}

The list of participants for the 2019 workshop is presented here:

(i) External: Ben Fransden (Brigham Young University), Dustin Gilbert (University of Tennessee), Sara Haravifard (Duke University), Nirmal Ghimire (George Mason University), Efrain Rodriguez (University of Maryland), Daniel Shoemaker (University of Illinois at Urbana-Champaign), Hari Nair (University of Texas at El Paso), Junjie Yang (Central Michigan University), Weiwei Xie (Louisiana State University), Jared Allred (The University of Alabama), Byron Freelon (University of Louisville), and Steve Bennett (Naval Research Laboratory)

(ii) Internal: Adam Aczel (Spectroscopy), Arnab Banerjee (Spectroscopy), Stuart Calder (Diffraction), Tim Charlton (Large Scale Structures), Travis Williams (Spectroscopy), Jaime Fernandez-Baca (Spectroscopy), Lisa DeBeer-Schmitt (Large Scale Structures), Clarina dela Crurz (Diffraction), Matt Stone (Spectroscopy), Bryan Chakoumakos (Diffraction), Bianca Haberl (Sample Environment), Gary Lynn (Sample Environment), Chris Redmon (Sample Environment), Doug Abernathy (Spectroscopy), Mark Loguillo (Sample Environment), Ken Herwig (NTD), Wei Tian (Spectroscopy), Georg Ehlers (NTD), Barry Winn (Spectroscopy), Mark Lumsden (Spectroscopy)

The fourth edition of this workshop in 2019 followed a very similar format to the previous three versions. The detailed agenda is presented below: 
June 6, 2019

DoubleTree Hotel, Oak Ridge

\begin{tabular}{|c|c|c|}
\hline Time & Event & $\begin{array}{l}\text { Session Chair } \\
\text { and Scribe }\end{array}$ \\
\hline 8:30-9:00 am & Morning Coffee & \\
\hline $9: 00-10: 20 \mathrm{am}$ & $\begin{array}{l}\text { (i) Workshop Charge: Stuart Calder (9:00) } \\
\text { (ii) Welcome and Brief History of Neutron Scattering } \\
\text { at ORNL: Jaime Fernandez-Baca }(9: 05) \\
\text { (iii) Powder Diffraction Suite: Bryan Chakoumakos } \\
\text { (9:30) } \\
\text { (iv) Single Crystal Diffraction Suite: Bryan } \\
\text { Chakoumakos ( } 9: 45) \\
\text { (v) Diffraction Suite Discussion (10:00) }\end{array}$ & $\begin{array}{l}\text { Adam Aczel, Lisa } \\
\text { DeBeer-Schmitt }\end{array}$ \\
\hline $10: 20-10: 35 \mathrm{am}$ & Morning Break & \\
\hline $10: 35-12: 45 \mathrm{pm}$ & $\begin{array}{l}\text { (i) Science talks - Sara Haravifard (10:35), Ben } \\
\text { Fransden (10:55), Dustin Gilbert (11:15) } \\
\text { (ii) Time-of-flight Spectrometers: Matt Stone (11:35) } \\
\text { (iii) Triple axis spectrometers: Jaime Fernandez-Baca } \\
\text { (11:50) } \\
\text { (iv) Spectroscopy Suite Discussion (12:05) } \\
\text { (v) Group photo (12:25) }\end{array}$ & $\begin{array}{l}\text { Stuart Calder, Lisa } \\
\text { DeBeer-Schmitt }\end{array}$ \\
\hline $12: 45-1: 45 \mathrm{pm}$ & $\begin{array}{l}\text { Working Lunch - Introduction to the Quantum } \\
\text { Materials Initiative and Possible Collaborations }\end{array}$ & Clarina dela Cruz \\
\hline $1: 45-3: 45 \mathrm{pm}$ & $\begin{array}{l}\text { (i) Science talks - Nirmal Ghimire (1:45), Efrain } \\
\text { Rodriguez (2:05), Daniel Shoemaker (2:25) } \\
\text { (ii) Low-T/High-B - Current Capabilities: Chris } \\
\text { Redmon (2:45) } \\
\text { (iii) Low-T/High-B - Future Capabilities: Barry Winn } \\
\text { (3:05) } \\
\text { (iv) Low-T/High-B Discussion (3:25) }\end{array}$ & $\begin{array}{l}\text { Adam Aczel, Matt } \\
\text { Stone }\end{array}$ \\
\hline $3: 45-4: 00 \mathrm{pm}$ & Afternoon Break & \\
\hline $4: 00-6: 00 \mathrm{pm}$ & $\begin{array}{l}\text { (i) Science talks - Harikrishnan Nair (4:00), Weiwei } \\
\text { Xie ( } 4: 20) \text {, Jared Allred }(4: 40) \\
\text { (ii) High Pressure - Current Capabilities: Mark } \\
\text { Loguillo (5:00) } \\
\text { (iii) High Pressure - Future Capabilities: Gary Lynn } \\
(5: 20) \\
\text { (iv) High Pressure Discussion }(5: 40)\end{array}$ & $\begin{array}{l}\text { Stuart Calder, Matt } \\
\text { Stone }\end{array}$ \\
\hline $6: 00-8: 00 \mathrm{pm}$ & $\begin{array}{l}\text { Dinner at the DoubleTree Hotel } \\
10 \text { year plan for Quantum Materials and Neutrons }\end{array}$ & Clarina dela Cruz \\
\hline
\end{tabular}




\begin{tabular}{|c|c|c|}
\hline Time & Event & $\begin{array}{l}\text { Session Chair and } \\
\text { Scribe }\end{array}$ \\
\hline $8: 30-9: 00$ AM & Morning coffee & \\
\hline 9:00-10:30 am & $\begin{array}{l}\text { (i) Science Talks: Byron Freelon (9:00), Junjie } \\
\text { Yang ( } 9: 20) \\
\text { (ii) GP-SANS: Lisa DeBeer-Schmitt (9:40) } \\
\text { (iii) Magnetism Reflectometer: Tim Charlton } \\
\text { (9:55) } \\
\text { (iv) GP-SANS and Magnetism Reflectometer } \\
\text { Discussion (10:10) }\end{array}$ & $\begin{array}{c}\text { Adam Aczel, Travis } \\
\text { Williams }\end{array}$ \\
\hline $10: 30-10: 45 \mathrm{am}$ & Morning Break & \\
\hline $10: 45-12: 20 \mathrm{pm}$ & $\begin{array}{l}\text { (i) Science talks: Steve Bennett (10:45), } \\
\text { Arnab Banerjee (11:05) } \\
\text { (ii) HFIR Cold Guide Hall Re-optimization: } \\
\text { Georg Ehlers }(11: 25) \\
\text { (iii) MANTA: Adam Aczel }(11: 45) \\
\text { (iv) HFIR Upgrades Discussion (12:00) }\end{array}$ & $\begin{array}{l}\text { Stuart Calder, Travis } \\
\text { Williams }\end{array}$ \\
\hline $12: 20-1: 20 \mathrm{pm}$ & $\begin{array}{l}\text { Working Lunch: MANTID Software Discussion } \\
\text { and Feedback }\end{array}$ & Doug Abernathy \\
\hline $1: 20-2: 45 \mathrm{pm}$ & $\begin{array}{l}\text { (i) STS: Current Status and Technical Details: } \\
\text { Ken Herwig }(1: 20) \\
\text { (ii) STS: Quantum Materials Science: Mark } \\
\text { Lumsden (1:40) } \\
\text { (iii) Possible Muon Source at the SNS: Travis } \\
\text { Williams ( } 2: 00) \\
\text { (iv) STS and Muon Source Discussion (2:20) }\end{array}$ & $\begin{array}{l}\text { Adam Aczel, Wei } \\
\text { Tian }\end{array}$ \\
\hline $2: 45-3: 00 \mathrm{pm}$ & Meeting close-out & $\begin{array}{l}\text { Adam Aczel / Stuart } \\
\text { Calder }\end{array}$ \\
\hline $3: 00-4: 00 \mathrm{pm}$ & Optional tours of the SNS and HFIR & $\begin{array}{l}\text { Adam Aczel / Stuart } \\
\text { Calder }\end{array}$ \\
\hline
\end{tabular}

\section{BRIEF HISTORY OF NEUTRON SCATTERING AT ORNL}

Since our external PIs ranged from experienced to prospective neutron scattering users, Jaime Fernandez-Baca presented a talk on the brief history of neutron scattering at ORNL to open the workshop. Jaime delivered a comprehensive summary on this topic. He started with an overview of the Manhattan Project, touched on the discovery of the neutron and the operation of the Graphite Reactor, explained the pioneering contributions of Cliff Shull and Ernie Wollan to neutron diffraction at ORNL, discussed the history and development of the High Flux Isotope Reactor, and talked about the construction of the Spallation Neutron Source at ORNL. His talk did an excellent job of setting the stage for the rest of the workshop. 


\section{QUANTUM MATERIALS YOUNG INVESTIGATOR SCIENCE}

This workshop series plays an important role in enhancing the Neutron Scattering Division's understanding of the key science drivers and important new trends in quantum materials research. Typically, this information has been communicated to NSD staff by having the external PIs present short science talks (15-20 minutes) at these workshops. These talks may concentrate on one specific project or research area that the PI's group is interested in, or they may provide a general overview of the PI's research program. Another important goal of these talks is for the PI to communicate how his/her group uses neutron scattering as a research tool now or plans to use the technique in the future. This information helps to inform NSD's investments in ORNL's quantum materials neutron scattering program.

We had 12 external PIs present scientific talks in the 2019 workshop, and Arnab Banerjee (Spectroscopy) also discussed some of the science that his group plans to pursue when he begins his Assistant Professor appointment at Purdue University in Jan. 2020. Based on the scientific talks, the research expertise of the external PIs is as follows:

1. Ben Frandsen (Brigham Young University): Neutron diffraction, pair-distribution function, and muon spin relaxation studies of quantum materials, including Fe-based superconductors

2. Dustin Gilbert (University of Tennessee): Small angle neutron scattering (SANS) studies of new skyrmion candidates

3. Sara Haravifard (Duke University): Neutron diffraction and spectroscopy studies of frustrated and quantum magnets under extreme conditions

4. Nirmal Ghimire (George Mason University): Neutron diffraction studies of correlated topological materials

5. Efrain Rodriguez (University of Maryland): Neutron diffraction studies of novel magnets and functional inorganic materials

6. Daniel Shoemaker (University of Illinois at Urbana-Champaign): Neutron diffraction studies of novel magnets, semiconductors, and materials with complex electronic interactions

7. Hari Nair (University of Texas at El Paso): Neutron diffraction studies of complex magnetic oxides

8. Junjie Yang (New Jersey Institute of Technology): Neutron diffraction and spectroscopy studies of quantum materials

9. Weiwei Xie (Louisiana State University): Neutron diffraction studies of quantum materials

10. Jared Allred (The University of Alabama): Neutron diffraction studies of functional inorganic materials

11. Byron Freelon (University of Houston): Neutron diffraction and spectroscopy studies of stronglycorrelated electron systems and low-dimensional materials

12. Steve Bennett (Naval Research Laboratory): Neutron reflectometry studies of magnetic thin films and interfaces

13. Arnab Banerjee (Purdue University, Jan. 2020): Neutron diffraction and spectroscopy studies of frustrated and low-dimensional quantum magnets

\section{THE QUANTUM MATERIALS INITIATIVE IN THE NEUTRON SCIENCES DIRECTORATE}

The Quantum Materials Initiative in the Neutron Sciences Directorate, currently led by Clarina dela Cruz, was founded in 2017. Since that time, Clarina has presented a talk at each Quantum Materials Young Investigators workshop that explains the charge of this initiative. She also covers recent activities that have been organized or sponsored by the initiative, including funding proposals, workshops, and educational opportunities. Finally, she discusses graduate student and postdoctoral fellowship opportunities in the Neutron Sciences Directorate at ORNL. The feedback from the external PIs on Clarina's talk is generally quite positive, as they are often not aware of all the neutron scattering learning and collaboration opportunities available for both themselves and their graduate students. Therefore, 
Clarina's talk is typically an excellent outreach platform and an effective way for the external PIs and NSD staff to begin new collaborations or enhance existing ones. Clarina has generally been presenting her talk during a working lunch on the first day of the workshop to ensure that there is plenty of time for informal discussions and networking during the remainder of the workshop.

\section{NEUTRON SCATTERING INSTRUMENT SUITES}

Since one of the goals of this workshop series is to attract new quantum materials neutron scattering users to ORNL, we typically present overviews of the various instruments important for quantum materials research. We also discuss recent instrument upgrades in these talks. More specifically, the topics covered included the following.

\section{1: Powder Diffraction}

This talk covered the powder diffraction suite, which includes NOMAD, POWGEN, HB-2A, and WAND $^{2}$. Highlights included the following topics: (1) implementing new closed cycle refrigerator and cryostat sample changers at HB-2A that will lead to higher throughput, and (2) commissioning the recent POWGEN upgrade that will lead to faster data collection.

\section{2: Single Crystal Diffraction}

This talk covered the single crystal diffraction suite, which includes TOPAZ, MANDI, CORELLI, DEMAND, IMAGINE, and WAND ${ }^{2}$. Highlights included the following topics: (1) implementing a significant detector upgrade at DEMAND that enables the instrument to operate in a twoaxis mode that can accommodate complex sample environments, and (2) commissioning the new 2D position-sensitive detector at $\mathrm{WAND}^{2}$ that will allow for increased data collection efficiency and stroboscopic measurements.

\section{3: Direct Geometry Spectroscopy}

This talk covered the direct geometry spectroscopy suite, which includes CNCS, HYSPEC, ARCS, and SEQUOIA. Highlights included the following topics: (1) purchasing a lower background, toploading CCR for ARCS that will enable users to perform their own sample changes, (2) developing a six sample changer for polycrystalline samples on ARCS that will increase instrument throughput, (3) installing an elevator at HYSPEC that allows users to switch from non-polarized to polarized mode easily, (4) adding new radial collimators to both CNCS and SEQUOIA to significantly reduce background, and (5) procuring a $14 \mathrm{~T}$ vertical field cryomagnet to enable a new class of spectroscopy experiments on quantum materials.

\section{4: Triple Axis Spectroscopy}

This talk covered the triple axis spectroscopy suite, which includes HB-1A, HB-1, HB-3, and CTAX. Highlights included the following topics: (1) rebuilding the monochromator system of HB-1A to move the vertical beam focus to the sample position, with an anticipated $3 \mathrm{x}$ gain in flux, (2) implementing Wollaston Prism technology at HB-1 for ultra-high resolution diffraction and spectroscopy, (3) purchasing new Heusler crystals to improve the polarization capability at HB-1, (4) adding a velocity selector to HB-3 to reduce background, and (5) reconfiguring the HFIR cold guide hall during the next Be reflector changeout in 2024 to enable the implementation of several upgrades and the construction of new world-class instruments, including a modern cold triple axis spectrometer MANTA. It is anticipated that MANTA will have an interchangeable backend with both traditional single analyzer-detector and multiplexed secondary spectrometer options. 


\section{5: Small Angle Neutron Scattering}

While this talk focused primarily on GP-SANS, it also contained some information on EQ-SANS since some proof-of-principle quantum materials experiments are now being performed there. Highlights included the following topics: (1) implementing a collimator upgrade at GP-SANS that will reduce background and increase flexibility to add polarization upgrades, and (2) modifying the EQ-SANS sample chamber to enable complex sample environment experiments.

\section{6: Reflectometry}

This talk discussed the magnetism reflectometer at the SNS. Highlights included the following topics: (1) commissioning of a large $2 \mathrm{GPa}$ pressure cell, and (2) procuring a $5 \mathrm{~T}$ open-bore magnet for the instrument.

\section{SAMPLE ENVIRONMENT}

Quantum materials studies often require low temperatures, high magnetic fields, and/or applied pressures. Therefore, 'low T/high B' and 'high pressure' sample environment support, capabilities, and developments are extremely important to ensure the continued success of a neutron scattering program in this important research area. Each workshop in this series now consists of two talks in each of these sample environment focus areas. The first talk provides an overview of the current capabilities and the second talk discusses active developments and future desires. We also remind the external PIs of the two relevant sample environment steering committees, who is chairing them and the charge and role of these committees in NSD. Finally, there is an extended discussion with the external PIs where we solicit their feedback in the two different sample environment focus areas.

\section{1: Sample Environment Steering Committees}

There are four sample environment steering committees in NSD: (i) high magnetic field, low temperature, (ii) high temperature, (iii) high pressure, and (iv) soft matter. These committees help NSD management to set priorities for acquiring new sample environment equipment in their respective areas and they work to improve operational reliability through discussion and advocation for critical spares, automation, and replacement of older equipment. These committees also stress the importance of best practices to obtain high quality data in the sample environments being used, and they listen to the needs of the user community to help ensure that the sample environment capabilities at ORNL's neutron scattering facilities are world-class. These committees provide justifications, applications for funding, prioritization of needs, and creation of specification documents to expand the equipment pool of sample environments. Finally, these committees work with potential LDRD teams at ORNL to develop and prioritize sample environment proposals.

\section{2: Low Temperature, High Magnetic Fields}

Most of the quantum materials neutron scattering experiments at ORNL require sample environment capabilities that are part of this focus area. The relevant sample environment steering committee is led by Barry Winn and is quite active. Several new low T/high B sample environments are being commissioned now or in procurement, including a $14 \mathrm{~T}$ vertical field magnet for the direct geometry spectrometers and CORELLI at the SNS, a $6 \mathrm{~T}$ vertical field magnet for HFIR to replace MAG$\mathrm{B}$, and a $5 \mathrm{~T}$ open-bore magnet for the SNS that will be used at EQ-SANS and the magnetism reflectometer. We also have an $11 \mathrm{~T}$ vertical field cryomagnet already in-house that we are hoping can replace MAG-D in the near future, which ran exclusively on CTAX until it reached its end of life. Finally, we have just finished commissioning two He-3 closed cycle refrigerators for HFIR. These are push-button systems that should require limited sample environment technician support and hopefully will enable us to run He-3 experiments more routinely in the future.

Low sample environment staffing levels have been a longstanding concern in this area, and this topic was discussed again at the 2019 workshop. The long-term goal of our sample environment group 
leader Gary Lynn is to staff a low T/high B sample environment team with a working team lead and eight additional members providing operational support. Four members of this team will be based at the SNS and the team lead plus the other four will be based at HFIR. This team is currently short two staff members and we are actively working to fill these open positions. We are also taking other steps to address low sample environment staffing levels, including the following: (1) Implementation of cryogen autofill systems wherever possible. Several systems are operable at the SNS and this technology has also now been tested successfully at HB-2A and CTAX. (2) Implementation of sample changers, particularly for experiments on polycrystalline samples. HB-2A recently commissioned both cryostat $(1.5 \mathrm{~K})$ and closed cycle refrigerator $(4 \mathrm{~K})$ sample changers, and ARCS is developing a closed cycle refrigerator sixsample changer. Plans for sample changers that reach $<1 \mathrm{~K}$ are underway at HFIR.

Another chronic sample environment concern has been the lack of after-hours support. Over the last few years, this issue has been addressed by expanding the instrument hall coordinator's role to include support of HFIR instruments. Users with sample environment issues after hours are now expected to call the instrument hall coordinator, who then calls the appropriate sample environment staff member from their call-down list. The instrument teams believe that this system is now working quite well, and typically after-hours issues are addressed in a relatively efficient manner.

\section{Feedback from quantum materials workshop participants:}

(1) Operating a CCR on NOMAD with a base temperature of $5-10 \mathrm{~K}$ base is important. There is an autochanger being fabricated for NOMAD that will operate in the $6-800 \mathrm{~K}$ temperature range.

(2) Moving to cryogen-free sample environments is a smart choice when and if it is possible.

(3) Horizontal field magnets with the small dark angles required for diffraction and spectroscopy instruments provide unique experimental capabilities that are currently not available at ORNL. For example, specific sample geometries may require horizontal fields to access the magnetic Bragg peaks or magnetic excitations of interest.

(4) A uniaxial strain device where the user can modify the strain in-situ would be very useful for many of the diffraction instruments, and possibly for some of the spectroscopy instruments as well.

(5) Strategic hires for the sample environment team with demonstrated technical expertise in magnets and low temperature systems would be an excellent investment and should be a top priority for the Neutron Scattering Division. Related to this point, the staffing level of the magnet and low temperature team needs to be increased effective immediately to ensure that the excellent, overworked technical staff on this team do not get burnt out and so all approved general user experiments requiring complex sample environments can be accommodated.

(6) Symmetry-breaking fields, which may be electric or magnetic in nature, are excellent quantum tuning parameters and therefore among the prime requirements for the study of new quantum materials. Combining magnetic fields with ultra-low temperatures helps to traverse the phase diagram of several materials and often spawns new, sometimes exotic, phases. Common split coil magnets of various sizes, including vector magnets which are compatible with several beamlines (such as the DGS and triple axis spectrometer suites, CORRELI, and eventually MANTA) are therefore a prime requirement for the neutron program.

(7) Generally, a challenge of performing a low-temperature measurement at the SNS with a magnet is the high magnet background, which requires the use of a radial collimator. While HYSPEC and CNCS currently have these radial collimators, which was easier to implement because the sample space is not in vacuum, they have not been implemented at ARCS, CORELLI and SEQUOIA. Therefore, the community is losing a prime opportunity to study field-induced phenomena using thermal neutrons. This should be a priority for the neutron program, especially given the overlap with the National Quantum mandate which includes study of new quantum materials and their ground states. 


\section{3: High Pressure}

There has recently been a significant increase in the number of neutron-scattering user experiments that require a pressure cell. In fact, there is now a High-Pressure Science Initiative in NSD. There is also a high-pressure sample environment steering committee that is led by Yan Wu and quite active. We can run experiments with gas cells, clamp cells, Paris-Edinburgh press and diamond anvil cells (DACs). There are plans to summarize our current list of pressure cells and make this information available in an online database for the user community, but that list has not been finalized yet. For now, some essential information about each type of cell is provided below:

The gas cells offer in-situ pressure changes and the lowest backgrounds, but the maximum pressures are typically only about $0.6 \mathrm{GPa}$ and this constraint is typically quite restrictive for quantum materials. Support is provided by the high-pressure sample environment team of Mark Loguillo and Matt Rucker.

The pressure range for clamp cells can vary quite dramatically. Although many of our cells top out at 2 $\mathrm{GPa}$ or less, the newly developed McWhan cell will allow applied pressures up to $10 \mathrm{GPa}$. The sample space of the clamp cell is in the intermediate range and is therefore quite suitable for various neutron diffraction and inelastic neutron scattering investigations. These cells have either minimal dark angles or none. The background is dependent on the cell design and it generally contaminates a substantial amount of reciprocal space, both in elastic and inelastic measurements. Currently, most of the clamp cells don't support in-situ pressure changes. Careful planning and loading are essential in obtaining hydrostatic pressures and completing successful experiments. Interested users should contact the relevant instrument team before they submit a clamp cell proposal.

The Paris-Edinburgh press is used at the SNAP beamline and is under testing at HYSPEC and WAND $^{2}$. This cell allows in-situ pressure change, has a high maximum pressure of $20 \mathrm{GPa}$, and can accommodate a relatively large sample. However, its low temperature capability is limited and there is only a small vertical opening angle for scattering experiments. Interested users should contact the SNAP instrument scientists.

The DACs offer the highest pressures (up to $40 \mathrm{GPa}$ ), with the maximum value dependent on several factors including the use of polycrystalline vs single crystal diamonds for the anvils and culet sizes. Our current DAC model has a vertical opening angle of about 60 degrees and we are currently testing both in-situ and non in-situ change pressure change options. Various DACs have been tested on the SNAP, VISION, CORELLI, DEMAND, IMAGINE etc beamlines. The high pressure team at ORNL is now working towards enabling the usage of Versimax DACs in the general user program. However, the sample size is limited in the DACs and the background can be complex. Furthermore, significant participation from the users is expected in the sample preparation and loading process, and they should have considerable knowledge of high-pressure experiments and their sample's properties at ambient and low applied pressures before proposing a DAC neutron scattering experiment at ORNL. Interested parties should read the relevant information available on the ORNL neutron scattering sample environment webpage and also contact Bianca Haberl or Yan Wu for more information about the DACs.

\section{Feedback from quantum materials workshop participants:}

(1) It was suggested that some benchmarking data of cell backgrounds be made readily available to users. Some of this information is available directly from the high-pressure sample environment team, but it is not necessarily clear who to contact for specific requests.

(2) A complete database for our pressure cell inventory should be added to the Neutron Sciences website. Most users are not well-informed on our current high-pressure capabilities.

(3) Pressure cell experiment checklists for the different types of experiments we perform (i.e. gas cell, clamp cell, diamond anvil cell) could be provided on the Neutron Sciences website. For example, what are the logistical issues that need to be addressed before a user arrives onsite, or after the user is onsite but before the experiment starts? How far in advance should a user arrive before a pressure experiment? What are the sample considerations? Perhaps the local experts on the high-pressure steering committee could work on developing these checklists. 


\section{FUTURE NEUTRON SCATTERING AND COMPLEMENTARY CAPABILITIES AT ORNL}

There are several ongoing efforts to develop new neutron scattering and complementary capabilities at ORNL that will enhance the quantum materials user program. Several workshop talks provided updates on these projects.

\section{1: HFIR Cold Guide Hall Re-optimization}

Georg Ehlers presented a talk that discussed our plans to re-optimize the HFIR cold guide hall after the next Be reflector change in 2024. The main highlights are as follows: (1) a new cold triple axis spectrometer, MANTA, will be built at the CG-1 position, (2) the cold guide hall building will be extended to accommodate a new cold neutron imaging and spin echo instrument, (3) the CG-4 guide will be split into several end stations to accommodate IMAGINE, an alignment station, and the spin echo instrument. Georg also mentioned that the long-term future of HFIR is now being actively discussed, including a possible replacement of the pressure vessel that would significantly extend the lifetime of the facility. There are also some long-term upgrade discussions taking place about building a new cold guide hall off the HB-2 beam port and then converting the current HB-4 cold guide hall to a thermal guide hall.

\section{2: MANTA}

The quantum materials community will really benefit from the addition of a world-class cold triple axis spectrometer, MANTA, to the ORNL neutron scattering spectroscopy suite. The current status of this project was presented at the 2019 workshop by Adam Aczel. This new instrument will enable neutron scattering experiments not possible elsewhere at ORNL due to a combination of its excellent signal-tonoise ratio, unique multiplexed backend, and polarization capabilities. The MANTA project is currently being led by Adam Aczel from ORNL and Martin Mourigal from Georgia Tech. Other members of the MANTA team from ORNL include Barry Winn, Garrett Granroth, and Gabriele Sala. The MANTA team is currently pursuing instrument funding from external sources, particularly for the multiplexed secondary spectrometer. Instrument design and simulations are also underway for the primary spectrometer and they are just beginning now for the secondary spectrometer. It is anticipated that the CAMEA-like concept for analyzer-detector multiplexing will be implemented on the backend of this instrument.

\section{3: Second Target Station}

A project office for the Second Target Station (STS) has now been established at ORNL and a CD-1 review is expected in late 2019 or 2020 . The current status of this project and the technical details for STS were presented at the 2019 workshop by Ken Herwig. A description of possible early science experiments was presented by Mark Lumsden. Although the initial instruments that will be built at STS have not been chosen yet, the quantum materials community is particularly interested in the cold chopper spectrometers CHESS and HERTZ, the magnetic diffractometer VERDI, and the ultra-high magnetic field beamline ZEEMANS.

\section{4: Muon Spectroscopy Facility}

Travis Williams from ORNL and Despina Louca from the University of Virginia are leading an effort to bring a muon spectroscopy facility to the SNS. Muon spin relaxation is a complementary probe to neutron scattering, especially for magnetic materials with weak moments. In fact, three out of the four muon spectroscopy facilities around the world are co-located with neutron sources. Travis presented a talk at the 2019 workshop describing the current status of this project. The proposed funding model would combine the muon spectroscopy facility with a single event effects testing facility, as the latter is particularly attractive to prospective industry partners, including airplane manufacturers such as Boeing. Travis is currently leading the R\&D effort at ORNL for the muon spectroscopy facility and pursuing external funding for the combined facility. The key idea here is to use laser stripping to generate a proton beam with the desired characteristics for these two facilities, which would have no significant impact on 
neutron production for the SNS and STS. It is anticipated that the muon source at the SNS would have the highest flux and resolution of any pulsed facility in the world.

\section{DATA REDUCTION, VISUALIZATION, AND ANALYSIS}

There were no specific talks in this area at the 2019 workshop due to major impending changes, but it is an extremely important topic that will generally be discussed in this workshop series in detail. There are a few important points to communicate here: (1) Jay Jay Billings is now the leader of the relevant group in the Neutron Scattering Division and it is now more focused on software engineering. (2) A Department of Energy review on data reduction, visualization, and analysis was just completed in July after the 2019 workshop took place. The Neutron Scattering Division's plan for addressing the shortcomings in this area was well-received by the review panel. This plan will be made available to interested parties upon request. (3) The primary goal of Jay's group right now is to normalize and improve the data reduction procedure across the SANS instrument suite.

We did have a working lunch discussion on this topic in the 2019 workshop, where the external PIs had the opportunity to provide general feedback about the state of neutron scattering data reduction, visualization, and analysis. We tried to concentrate on the current state of Mantid in this discussion. A summary of the participant feedback is presented here:

(1) Adding quick folding/symmetrizing options to Mantid would help uncover weak scattering features during experiments and therefore improve data collection efficiency.

(2) There is a desire to implement a 'no-frills' version of this software that may be able to create basic plots faster than the current version. For example, the basic plots could use fixed binning algorithms and neglect error bars.

(3) Mantid has a steep learning curve, so the users need more documentation, tutorials, webinars etc. to make it more user-friendly. Perhaps NSD can develop a script/tutorial library.

(4) There are many Mantid features that most users still don't know about, so we need more efficient ways to communicate the capabilities of this software to our users.

(5) Mantid should use standardized data formats to easily move between different pieces of software (e.g. Nexus files).

(6) We should establish clear expectations for what Mantid is expected to do well and what it should not do.

(7) There should be a clear, automated error reporting system. It should also be able to document and $\log$ errors, so repeated occurrences of the same bug can be identified.

(8) Be careful not to rely on Mantid for too much data analysis. Data analysis should not be prioritized over issues related to reduction and visualization.

(9) ORNL has a role to provide software that will enable users to go from data acquisition to visualization. However, data analysis software can be at least partially community driven.

\section{GENERAL PARTICIPANT FEEDBACK AND TESTIMONIALS}

(1) General workshop feedback

(i) Everybody agrees that it is appropriate for the external PIs to deliver 20-minute talks about their group's research interests at these workshops.

(ii) It was suggested to avoid combining future iterations of this workshop with the SHUG onsite meeting. The external PIs would also prefer the workshop to be held at ORNL and not at a hotel in Oak Ridge.

(iii) It would be nice if the external PIs had more time to interact with each other and build collaborations. Perhaps one option is to set aside some working group time. 
(iv) In future workshops, consider discussing machine learning or supercomputing approaches to studying quantum materials. Several external PIs are interested in collaboration opportunities between their groups and the machine learning/supercomputing experts at ORNL.

(2) Additional feedback and testimonials from specific workshop participants

(i) Efrain Rodriguez (2019)

Thanks so much for organizing this meeting and for inviting me for it. I learned quite a lot, and I am happy to see how much effort is going to be poured into quantum materials at ORNL.

From the science presented, it seems to me that the unique role that neutrons play in understanding magnetism, both structure and dynamics, will be increasingly important for the community. The new instruments planned for STS seem to be well aligned with this new effort, and I am particularly excited about VERDI and the high-magnetic field beam line ZEEMANS. My only concern here is that there is enough of a user base that takes advantage of this extensive suite of capabilities and that it doesn't just get used by the 'usual suspects.' I think continued outreach by ORNL to groups that make samples and grow crystals will be just as important as having state-of-the-art instrumentation. Likewise, instruments are just as good as the expertise to interpret the measurements. Retaining talented scientific staff that can help the user better understand their neutron results will be key to having neutron scattering play a central role in new quantum materials.

Facility-wise I was struck by how dire the situation seems for sample environment staffing. The staff levels are not commensurate with the high-level science and sophisticated measurements taking place at HFIR and SNS. It seemed unanimous among all the workshop attendants that the technical staff in the sample environment team needs to be increased in order to ensure successful execution of experiments that are awarded beam time. Otherwise, the neutron time allotted will be wasted, which is detrimental to both the facility and the end user.

(ii) Junjie Yang (2019)

The 2019 workshop discussed many critical and practical questions related to neutron scattering studies of quantum materials. As a junior faculty member in this field, I feel that the workshop is extremely helpful. The following is a list of key topics that we discussed at the workshop:

[1] Strengthen the polarization capabilities at ORNL. Polarized neutron scattering is an important aspect for the study of quantum materials, such as magnetic chirality. Neutron polarization upgrades will definitely be important for my group, as we are planning to study chiral quantum magnets in detail. I will also send my students to the polarization workshop at ORNL in September being organized by Ovi Garlea, Barry Winn et al.

[2] Build a new multi-analyzer cold triple axis instrument (MANTA) at HFIR. Cold triple axis spectroscopy is an essential tool for investigating the properties of quantum materials. We will have many crystals which may benefit from MANTA experiments characterizing their low energy spin excitations in the future.

[3] Consider a mail-in program for direct geometry spectroscopy measurements of polycrystalline samples. As a junior faculty member, I'm putting in significant effort to create new materials so that I can distinguish myself from senior researchers in this field. However, new materials also means that we know rather limited information about their dynamical properties. This makes our spectroscopy proposals seem somewhat risky to the science review committee and therefore these proposals typically have a low 
success rate. However, the most important scientific discoveries often come from the investigation of new materials. This mail-in program will be very helpful for the preliminary study of new polycrystalline materials.

Regarding the workshop itself, I had plenty of time to talk to instrument scientists about possible neutron scattering experiments on new single crystals produced by my group. These discussions were quite fruitful and will certainly help to speed up my group's research projects.

(iii) Ben Frandsen (2019)

The 2019 Quantum Materials Young Investigators meeting was a valuable experience for me. In addition to learning more about the current and planned capabilities at ORNL to carry out research in quantum materials, I had the opportunity to interact closely with my peers in the field, learn about their research, and communicate to ORNL staff the needs and priorities we have as early-career scientists in our field. I left the meeting with multiple potential collaborations on exciting projects and an expanded sense of what I can accomplish with neutrons (and hopefully muons in the future) at ORNL.

(iv) Weiwei Xie (2019)

Thank you very much for your hard work on the workshop! It is so wonderful and detailed; I got a lot of useful information from the workshop!

(v) Steve Bennett (2019)

Participating in the Quantum Materials Young Investigator Workshop gave me the opportunity to interface with other neutron scientists in the field and broaden my knowledge of what is possible with neutron science. As a DoD researcher scientist, it also gives me an optimal setting to connect with DOE scientists and academic professors in interdisciplinary fields.

(vi) Sara Haravifard (2019)

I have had the pleasure to attend 3 out of 4 "Quantum Materials Young Investigators Workshops" at ORNL, and in addition to learning about capabilities and new developments coming online at ORNL NScD facilities every year, I also had the opportunity to get to know many of my peers and learn about their research interests much better. I can identify two major accomplishments as result of attending these workshops: (1) I have established a very productive and on-going collaboration with two other attendees; (2) I got to learn about HFIR capabilities and after being a sole user of SNS for many years, we have started to use HFIR facility. My team and I have had several successful experiments performed at HFIR since, for which two publications are under preparation. I would like to thank the organizers of these workshops, Dr. Aczel and Dr. Calder, for their leadership and vision, and truly hope that these annual workshops continue.

(vii) Jared Allred (2019)

Discussions with other scientists at similar stages in their careers helped me better learn how to identify and assert my independent approach and viewpoint as a researcher. This development was invaluable in building my confidence and focusing my efforts during the difficult first few years as an independent researcher.

(viii) Xianglin Ke (2018) 
Thanks to you for successfully organizing the 'Quantum Materials Young Investigators Workshop' and inviting me to attend the workshop in the past few years. I highly appreciate this workshop as it provides an excellent platform to young neutron scatters to exchange scientific ideas and to strengthen their bonds with the colleagues in ORNL.

(ix) Christianne Beekman (2018)

The Quantum Materials Young Investigators Workshop is an incubator for young researchers to start new collaborations and to learn about the state-of-the-art neutron facilities at ORNL. The collaboration that I started during the workshop in Aug. 2016 has already led to successful neutron studies and a publication in Physical Review Materials.

(x) Stephen Wilson (2018)

The Quantum Materials Young Investigator Workshops have been invaluable to me and my research group. They not only provide exposure to the latest neutron capabilities at ORNL through research examples but also allow interactions among junior PIs in troubleshooting research problems. I've received very helpful idea at these workshops, and I've tried to provide some of my own to others. "Soft" benefits include crucial networking amongst young faculty establishing their research groups with those who have only just recently done so, and I think this certainly helps promote the growth of the domestic neutron scattering community.

(x) Valentin Taufour (2018)

The workshop was very informative of ORNL's capabilities and an incredible opportunity to start new collaborations. Stuart and Adam organized one of the most useful workshops I ever attended. 


\section{QUANTUM MATERIALS YOUNG INVESTIGATORS MASTER LIST AND PAST WORKSHOP PARTICIPANTS}

Table 1: Quantum Materials Young Investigators Master List and Past Workshop Participants

\begin{tabular}{|c|c|c|}
\hline Name and Institution & Email Address & Years Attended \\
\hline $\begin{array}{l}\text { 1. Kate Ross, Colorado State } \\
\text { University }\end{array}$ & rosska2@rams.colostate.edu & 2016 \\
\hline $\begin{array}{l}\text { 2. Xianglin Ke, Michigan } \\
\text { State University }\end{array}$ & ke@pa.msu.edu & 2016,2017 \\
\hline $\begin{array}{l}\text { 3. Deepak Singh, University } \\
\text { of Missouri }\end{array}$ & singhdk@missouri.edu & 2016,2018 \\
\hline $\begin{array}{l}\text { 4. Sara Haravifard, Duke } \\
\text { University }\end{array}$ & haravifard@phy.duke.edu & $2016,2017,2019$ \\
\hline $\begin{array}{l}\text { 5. Martin Mourigal, Georgia } \\
\text { Institute of Technology }\end{array}$ & mourigal@gatech.edu & 2016,2017 \\
\hline $\begin{array}{l}\text { 6. Ni Ni, University of } \\
\text { California - Los Angeles }\end{array}$ & nini@physics.ucla.edu & 2016 \\
\hline $\begin{array}{l}\text { 7. Greg MacDougall, } \\
\text { University of Illinois at } \\
\text { Urbana-Champaign }\end{array}$ & gmacdoug@,illinois.edu & $2016,2017,2018$ \\
\hline $\begin{array}{l}\text { 8. Edwin Fohtung, New } \\
\text { Mexico State University }\end{array}$ & efohtung@nmsu.edu & 2016,2017 \\
\hline $\begin{array}{l}\text { 9. Christianne Beekman, } \\
\text { Florida State University }\end{array}$ & beekman@magnet.fsu.edu & $2016,2017,2018$ \\
\hline $\begin{array}{l}\text { 10. Steve Bennett, Naval } \\
\text { Research Laboratory }\end{array}$ & steven.bennett@,nrl.navy.mil & 2016,2019 \\
\hline $\begin{array}{l}\text { 11. Corey Thompson, Purdue } \\
\text { University }\end{array}$ & cmthompson@purdue.edu & 2018 \\
\hline $\begin{array}{l}\text { 12. Jared Allred, The } \\
\text { University of Alabama }\end{array}$ & jmallred@ua.edu & 2017,2019 \\
\hline $\begin{array}{l}\text { 13. Kemp Plumb, Brown } \\
\text { University }\end{array}$ & kemp_plumb@brown.edu & 2017,2018 \\
\hline $\begin{array}{l}\text { 14. Steve May, Drexel } \\
\text { University }\end{array}$ & smay@coe.drexel.edu & 2018 \\
\hline $\begin{array}{l}\text { 15. Byron Freelon, University } \\
\text { of Houston }\end{array}$ & bkfreelon@uh.edu & 2019 \\
\hline $\begin{array}{l}\text { 16. Fazel Tafti, Boston } \\
\text { College }\end{array}$ & fazel.tafti@,bc.edu & \\
\hline $\begin{array}{l}\text { 17. Jeff Quilliam, Universite } \\
\text { de Sherbrooke }\end{array}$ & Jeffrey.Quilliam@USherbrooke.ca & \\
\hline $\begin{array}{l}\text { 18. Daniel Shoemaker, } \\
\text { University of Illinois at } \\
\text { Urbana-Champaign }\end{array}$ & dpshoema@,illinois.edu & 2018,2019 \\
\hline $\begin{array}{l}\text { 19. Junjie Yang, Central } \\
\text { Michigan University }\end{array}$ & yang6j@cmich.edu & 2018,2019 \\
\hline $\begin{array}{l}\text { 20. Ben Frandsen, Brigham } \\
\text { Young University }\end{array}$ & benfrandsen@gmail.com & 2019 \\
\hline
\end{tabular}




\begin{tabular}{|c|c|c|}
\hline $\begin{array}{l}\text { 21. Dustin Gilbert, University } \\
\text { of Tennessee }\end{array}$ & dagilbert@utk.edu & 2019 \\
\hline $\begin{array}{l}\text { 22. Nirmal Ghimire, George } \\
\text { Mason University }\end{array}$ & nghimire@gmu.edu & 2019 \\
\hline $\begin{array}{l}\text { 23. Chen Li, University of } \\
\text { California - Riverside }\end{array}$ & chen.li@ucr.edu & \\
\hline $\begin{array}{l}\text { 23. Efrain Rodriguez, } \\
\text { University of Maryland }\end{array}$ & efrain@umd.edu & 2019 \\
\hline $\begin{array}{l}\text { 24. Hari Nair, University of } \\
\text { Texas at El Paso }\end{array}$ & hnair@utep.edu & 2019 \\
\hline $\begin{array}{l}\text { 25. Weiwei Xie, Louisiana } \\
\text { State University }\end{array}$ & weiweix@1su.edu & 2019 \\
\hline $\begin{array}{l}\text { 26. Arnab Banerjee, Purdue } \\
\text { University (Jan. 2020) }\end{array}$ & banerjeea@ornl.gov & 2019 \\
\hline $\begin{array}{l}\text { 27. Julia Zaikina, Iowa State } \\
\text { University }\end{array}$ & yzaikina@iastate.edu & \\
\hline $\begin{array}{l}\text { 28. Alex Frano, University of } \\
\text { California - San Diego }\end{array}$ & afrano@physics.ucsd.edu & \\
\hline $\begin{array}{l}\text { 29. Joe Checkelsky, } \\
\text { Massachusetts Institute of } \\
\text { Technology }\end{array}$ & checkelsky@mit.edu & \\
\hline $\begin{array}{l}\text { 30. Ryan Baumbach, Florida } \\
\text { State University }\end{array}$ & baumbach@magnet.fsu.edu & 2018 \\
\hline $\begin{array}{l}\text { 31. Valentin Taufour, } \\
\text { University of California - } \\
\text { Davis }\end{array}$ & vtaufour@ucdavis.edu & 2018 \\
\hline $\begin{array}{l}\text { 32. Chetan Dhital, Kennesaw } \\
\text { State University }\end{array}$ & cdhital@kennesaw.edu & 2018 \\
\hline $\begin{array}{l}\text { 33. Alannah Hallas, } \\
\text { University of British Columbia }\end{array}$ & alannah.hallas@gmail.com & \\
\hline $\begin{array}{l}\text { 34. Bill Gannon, University } \\
\text { of Kentucky }\end{array}$ & wgannon@uky.edu & \\
\hline 35. Ming Yi, Rice University & mingyi@rice.edu & \\
\hline $\begin{array}{l}\text { 36. Stephen Wilson, } \\
\text { University of California - } \\
\text { Santa Barbara }\end{array}$ & stephendwilson@engineering.ucsb.edu & 2016,2017 \\
\hline $\begin{array}{l}\text { 37. Jamie Neilson, Colorado } \\
\text { State University }\end{array}$ & james.neilson@colostate.edu & 2017 \\
\hline $\begin{array}{l}\text { 38. Marc Janoschek, Paul } \\
\text { Scherrer Institute }\end{array}$ & marc.janoschek@psi.ch & 2017 \\
\hline $\begin{array}{l}\text { 39. Olivier Delaire, Duke } \\
\text { University }\end{array}$ & olivier.delaire@duke.edu & 2018 \\
\hline
\end{tabular}

